\title{
Excited State Proton Transfer as a Probe for Polymer-Surfactant Interaction
}

\author{
Dipankar Sukul, Samir Kumar Pal, Debabrata Mandal, Sobhan Sen, and \\ Kankan Bhattacharyya* \\ Physical Chemistry Department, Indian Association for the Cultivation of Science, \\ Jadavpur, Calcutta 700 032, India
}

Received: October 20, 1999; In Final Form: April 6, 2000

\begin{abstract}
Interaction between the polymer, poly(vinylpyrrolidone) (PVP) and an anionic surfactant (sodium dodecyl sulfate, SDS) has been studied using excited-state proton transfer (ESPT) of 1-naphthol as a probe. In aqueous solution, the ESPT process of 1-naphthol is very fast and occurs in $\sim 35 \mathrm{ps}$. The kinetics of the ESPT process remains unchanged on addition of $4 \mathrm{mg}$ PVP per $\mathrm{mL}$. However, on addition of SDS, in the presence of PVP, the ESPT process of 1-naphthol is retarded dramatically. Compared to ordinary water, the intensity of the emission of the neutral form of 1-naphthol (at $360 \mathrm{~nm}$ ) is enhanced 200 times in the presence of PVP (4 $\mathrm{mg}$ per $\mathrm{mL}$ ) and $15 \mathrm{mM}$ SDS. In the PVP-SDS complex, the anion emission of 1-naphthol shows a rise time of $1.6 \mathrm{~ns}$ and a decay of lifetime $13 \mathrm{~ns}$, while the neutral emission (at $360 \mathrm{~nm}$ ) exhibits a biexponential decay having components of 1.6 and $5.3 \mathrm{~ns}$. This indicates the existence of two kinds of environment in the SDSPVP aggregates. In one of them, ESPT of 1-naphthol is totally suppressed leading to a long lifetime (5.3 ns) of the neutral emission. In the other environment, ESPT occurs on a $1.6 \mathrm{~ns}$ time scale. The critical association concentration (CAC) of SDS for the PVP-SDS system is 10 times lower than the CMC of SDS.
\end{abstract}

\section{Introduction}

Interaction of polymer chains with surfactants is a subject of several recent studies. ${ }^{1-12}$ Recently, several groups investigated such interactions using fluorescence correlation spectroscopy, ${ }^{1}$ conductivity, ${ }^{4}$ fluorescence, $, 4,11$ light scattering, ${ }^{6}{ }^{\mathrm{NMR}},{ }^{9}$ and neutron scattering. ${ }^{12}$ Several theoretical models have been proposed to explain the thermodynamics of this process. ${ }^{3,5,8}$ In aqueous solutions, because of the hydrophobic effect, ${ }^{13}$ the polymers readily form aggregates with the surfactants above a particular surfactant concentration, known as the critical association concentration (CAC). The CAC for a polymersurfactant system is often very much lower than the critical micellar concentration (CMC) of the surfactant. ${ }^{1,3-11}$ According to the "necklace model", the polymer-surfactant aggregates consist of a series of spherical micelles surrounded by the polymer segments and connected by polymer strands (Scheme 1). ${ }^{5}$ Thus the polymer chain shields the peripheral region of the micelles from bulk water. Among the various polymersurfactant systems, poly(vinylpyrrolidone) (PVP) and sodium dodecyl sulfate (SDS) are, perhaps, the most well characterized. ${ }^{1,3-4}$ In a recent photon correlation study, ${ }^{1}$ it has been demonstrated that SDS forms micellar aggregates of a size $\sim 5$ $\mathrm{nm}$ at a concentration above CMC $(\sim 8 \mathrm{mM})$. However, in the presence of a small amount of PVP $(\sim 3 \mathrm{mg} / \mathrm{mL})$ very large aggregates $(\sim 12 \mathrm{~nm}$ for PVP with molecular weight, $\mathrm{M}=5 \times$ $10^{4} \mathrm{Da}$ and $\sim 35 \mathrm{~nm}$ for PVP with, $\mathrm{M}=10^{6} \mathrm{Da}$ ) are formed. The critical association concentration, i.e., the concentration corresponding to the break in the plot of size of aggregates vs surfactant concentration, is $\sim 0.3 \mathrm{mM}$ for SDS. ${ }^{1}$ This is far below the CMC of SDS $(8 \mathrm{mM})$. The CAC for the PVP-SDS system was found to be independent of the molecular weight of the polymer. ${ }^{1}$ However, the maximum size of the polymer-

*E-mail: pckb@mahendra.iacs.res.in. Fax: (91)-33-473-2805.
SCHEME 1: Schematic Representation of the "Necklace Model" of Polymer-Micelle Aggregation

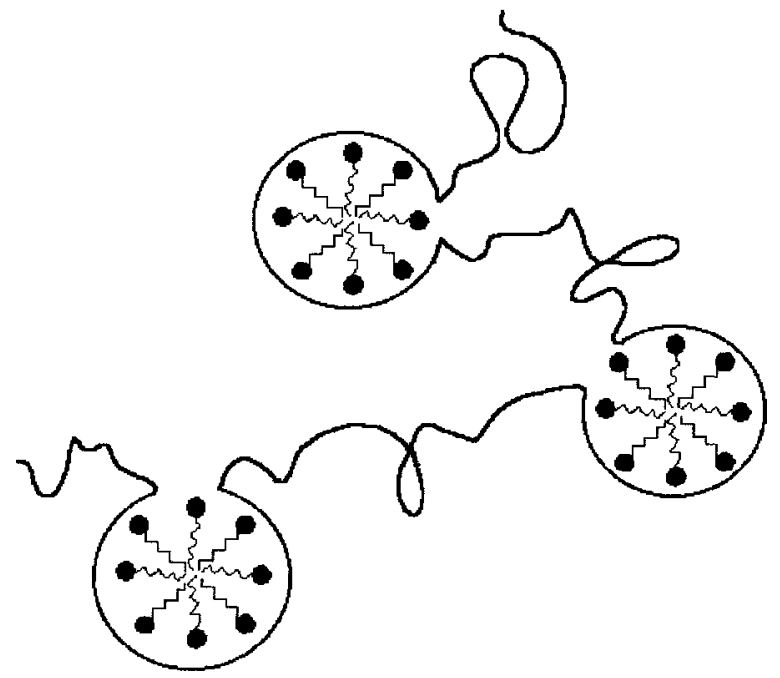

surfactant aggregates is found to increase with the molecular weight of the polymer. ${ }^{1}$

In the present work, we will demonstrate that the excited state proton transfer (ESPT) of 1-naphthol is a sensitive probe to study the interaction of PVP and SDS. 1-Naphthol undergoes very fast deprotonation in aqueous solution. ${ }^{14 a}$ As a result, the emission from the neutral form of 1-naphthol at $360 \mathrm{~nm}$ exhibits a decay of lifetime $35 \mathrm{ps}$ and the anion emission at $460 \mathrm{~nm}$ exhibits a 35 ps rise time. ${ }^{14 a}$ There have been several attempts to ascertain the number of water molecules needed to solvate the proton ejected from 1-naphthol. Robinson et al. proposed that in liquid solutions $3 \pm 1$ water molecules are needed to solvate the ejected proton. ${ }^{14 \mathrm{~b}}$ However, in ultracold supersonic jets, no ESPT is observed even in solvent clusters of 1-naphthol 
containing as many as 21 water molecules. ${ }^{15}$ This indicates that the local structures of the clusters in the beam are not favorable for the ESPT process. ${ }^{15 \mathrm{c}}$ In liquids, if adequate numbers of water molecules are not available in the immediate vicinity of the 1-naphthol molecule, the ESPT process is inhibited to a large extent. In an aqueous solution, when 1-naphthol binds to organized media such as cylclodextrin, ${ }^{16}$ micelles, ${ }^{17}$ or lipids, ${ }^{18}$ the number of water molecules around 1-naphthol decreases. This causes marked inhibition of the ESPT process. ${ }^{16-18}$ Fleming et al. ${ }^{16}$ showed that binding of 1 -naphthol to $\beta$-cyclodextrin causes a 25 -fold reduction in the rate of proton transfer. This results in a marked increase in the intensity and the lifetime of the emission from the neutral form and the rise time of the anion emission. On binding to micelles, the ESPT process of 1-naphthol is retarded significantly, causing a 20-90-fold increase in the intensity and lifetime of the neutral emission as well as in the rise time of the anion emission. ${ }^{17}$ Since the ESPT process of 1-naphthol is so sensitive to the environment, ${ }^{16-19}$ we have decided to investigate how the ESPT process is affected when 1-naphthol binds to an aggregate containing PVP and SDS.

\section{Experimental Section}

1-Naphthol (Merck, 99.9+\%) was purified by vacuum sublimation followed by recrystallization from 1:1 aqueous methanol. SDS (Aldrich) and PVP (M = $3 \times 10^{4}$ Da, Aldrich) were used as received. The steady state absorption and emission spectra were recorded in a JASCO 7850 spectrophotometer and a Perkin-Elmer 44B spectrofluorimeter, respectively. For lifetime measurement, the sample was excited at $300 \mathrm{~nm}$ by the second harmonic of a cavity-dumped dual jet Rhodamine 6G/DODCI dye laser (Coherent 702-1) pumped by a cw mode-locked Nd: YAG laser (Coherent Antares 76s). The emission was detected at magic angle polarization using a Hamamatsu MCP photomultiplier (2809U). The fluorescence decays were deconvoluted using a global lifetime analysis software (PTI).

\section{Results}

3.1 Steady State Spectra. In aqueous solution, emission from the neutral form of 1-naphthol at $\sim 360 \mathrm{~nm}$ is very weak $\left(\phi_{\mathrm{f}}=\right.$ 0.002 ) while the anion emission at $\sim 460 \mathrm{~nm}$ is moderately strong $\left(\phi_{\mathrm{f}}=0.11\right) .{ }^{14,17} \mathrm{On}$ addition of $4 \mathrm{mg}$ PVP to $1 \mathrm{~mL}$ of a $4 \times 10^{-5} \mathrm{M}$ aqueous solution of 1-naphthol, the intensity of the neutral and the anion forms increases marginally (Figures 1 and 2). On gradual addition of SDS to this solution, the intensity of the neutral and the anion form remain unchanged up to about $0.8 \mathrm{mM}$ SDS. On further increase in SDS concentration, the intensity of the neutral emission increases rapidly (Figures 1 and 2). It may be noted that in the absence of PVP, the emission intensity of 1-naphthol shows a break at $8 \mathrm{mM}$ (i.e., CMC of SDS). ${ }^{17}$ Thus, in the presence of $4 \mathrm{mg}$ PVP per $\mathrm{mL}$, the intensity of the emission from the neutral form of 1-naphthol starts to increase at a concentration at least 10 times smaller than the CMC of the surfactant, SDS. The concentration at which the fluorescence intensity starts to increase is the CAC for the PVP-SDS system. Thus in this case CAC is $0.8 \mathrm{mM}$. According to the photon correlation study, ${ }^{1}$ the size of the PVP-SDS aggregates starts to increase at an SDS concentration of $0.3 \mathrm{mM}$. Thus, the break in the emission intensity of the neutral form of 1-naphthol is close to that observed in the photon correlation study. ${ }^{1}$

With gradual increase in SDS concentration in the presence of PVP ( $4 \mathrm{mg} / \mathrm{mL})$, the intensity of the $360 \mathrm{~nm}$ emission band increases rapidly, reaching a maximum enhancement of $\sim 200$ times at $\sim 15 \mathrm{mM}$ of SDS (Figure 2). The photon correlation

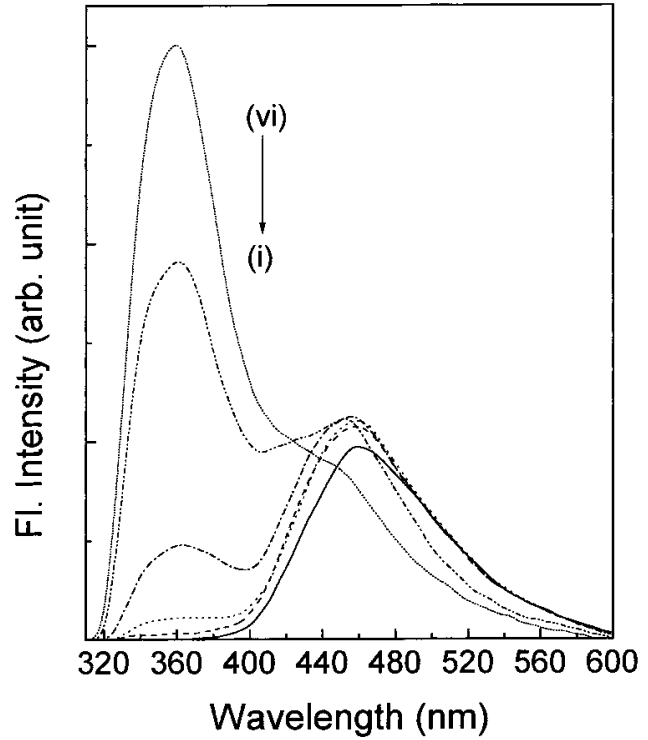

Figure 1. Emission spectra of $4 \times 10^{-5} \mathrm{M}$ aqueous solution of 1-naphthol with (i) no PVP and SDS, (ii) $4 \mathrm{mg}$ PVP per mL, (iii) PVP and $1.5 \mathrm{mM}$ SDS, (iv) PVP and $2.5 \mathrm{mM}$ SDS, (v) PVP and $5 \mathrm{mM}$ SDS, and (vi) PVP and $15 \mathrm{mM}$ SDS.

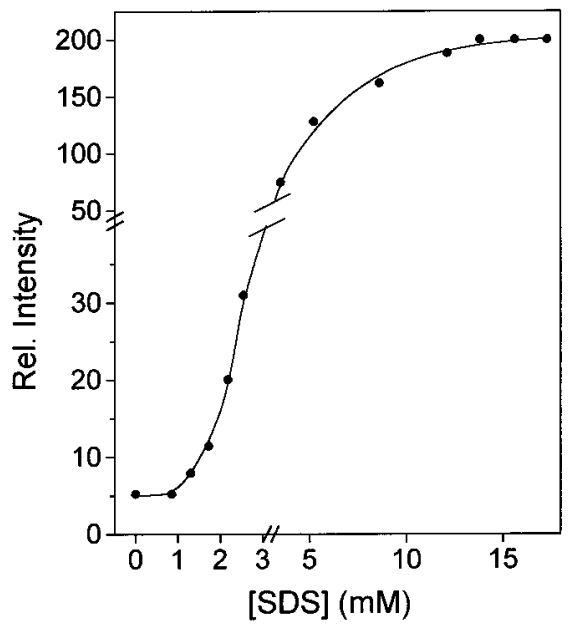

Figure 2. Plot of intensity of the $360 \mathrm{~nm}$ band of 1-naphthol relative to water for a $4 \times 10^{-5} \mathrm{M}$ aqueous 1-naphthol solution containing 4 $\mathrm{mg}$ PVP per $\mathrm{mL}$ against the concentration of SDS.

study also indicates that the size of the aggregate increases with SDS concentration and levels off at $\sim 15 \mathrm{mM} .{ }^{1}$ It may be recalled that the magnitude of emission enhancement caused by SDS alone is much less. ${ }^{17}$ The $15 \mathrm{mM}$ SDS alone causes a $\sim 30$-fold enhancement of the neutral emission of 1-naphthol, while the maximum enhancement of $\sim 90$ times is attained at a far higher SDS concentration of $\sim 140 \mathrm{mM} .^{17}$ This indicates that, in the presence of PVP, 1-naphthol experiences a microenvironment very different from that in the SDS micellar aggregates. The absorption spectrum of 1-naphthol in a solution containing $15 \mathrm{mM}$ SDS and $4 \mathrm{mg}$ PVP per $\mathrm{mL}$ (against a solution of SDS and PVP as reference) is shown in Figure 3. Figure 3 also shows the excitation spectra of the neutral (360 $\mathrm{nm})$ and the anion emission $(460 \mathrm{~nm})$ of the solution containing PVP and SDS. It is readily seen that the excitation spectra are identical to the absorption spectrum. This rules out the presence of any impurity.

It should be noted that while addition of SDS in the presence of PVP leads to a gradual increase in emission intensity of the neutral form reaching a maximum value asymptotically, the 


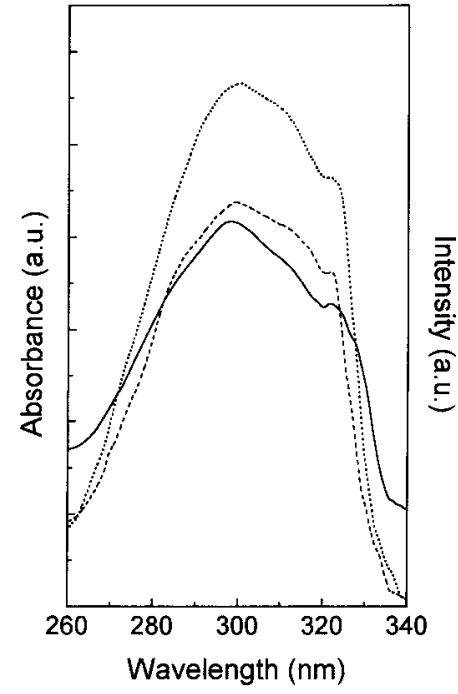

Figure 3. (i) Absorption spectrum (-), (ii) excitation spectrum at 460 $\mathrm{nm}(---)$, and (iii) excitation spectrum at $360 \mathrm{~nm}(\cdots)$ of $4 \times 10^{-5} \mathrm{M}$ aqueous 1-naphthol solution containing $15 \mathrm{mM}$ SDS and $4 \mathrm{mg}$ PVP per $\mathrm{mL}$.

behavior of the anion emission (at $460 \mathrm{~nm}$ ) is quite different. The intensity of the anion emission increases up to an SDS concentration of $5 \mathrm{mM}$. At higher SDS concentration, the intensity of the anion emission decreases (Figure 1).

3.2 Time-Resolved Studies. To determine the rate of ESPT of 1-naphthol bound to the PVP-SDS aggregates we have made a time-resolved study of the neutral emission at $360 \mathrm{~nm}$ and the anion emission at $480 \mathrm{~nm}$ (where contribution of the neutral form is negligible). It is observed that in the absence of SDS, in an aqueous solution containing $4 \mathrm{mg}$ PVP per $\mathrm{mL}$, 1-naphthol exhibits a very fast $(<80 \mathrm{ps})$ decay at $360 \mathrm{~nm}$ and a fast rise at $480 \mathrm{~nm}$, while the lifetime of decay at $480 \mathrm{~nm}$ is $\sim 8 \mathrm{~ns}$. These parameters are very similar to the decay parameters of the emission of neutral and anion forms of 1-naphthol in aqueous solutions. ${ }^{14}$ This indicates that in the absence of SDS, 1-naphthol does not bind to the polymer, PVP. In $15 \mathrm{mM}$ SDS and in the presence of $4 \mathrm{mg}$ PVP per $\mathrm{mL}$, the anion emission exhibits a rise time of $1.6 \mathrm{~ns}$ and a decay time of $13 \mathrm{~ns}$ (Figure 4a,b). The neutral emission exhibits a biexponential decay having components of $1.6 \mathrm{~ns}(12 \pm 3 \%)$ and $5.3 \mathrm{~ns}(88 \pm 3 \%)$ (Figure $4 \mathrm{a}-\mathrm{c}$ and Table 2). The emission parameters of 1-naphthol in the solution containing PVP and SDS are summarized in Table 1. Figure $4 \mathrm{c}$ shows the decay of the neutral emission of 1-naphthol in PVP $(4 \mathrm{mg} / \mathrm{mL})$ at various SDS concentrations. As shown in Figure $4 \mathrm{c}$ and in Table 2, the relative contribution of the $5.3 \mathrm{~ns}$ component increases with SDS concentrations from $30 \pm 3 \%$ in $2.5 \mathrm{mM}$ SDS to $88 \pm 3 \%$ in $15 \mathrm{mM}$ SDS, with a concomitant decrease in the contribution of the $1.6 \mathrm{~ns}$ component from $70 \pm 3 \%$ to $12 \pm 3 \%$.

It is evident that the temporal characteristics of the emission at 360 and $480 \mathrm{~nm}$ are different from those of 1-naphthol bound to SDS. In a previous study, we observed that in $200 \mathrm{mM}$ SDS, the neutral form of 1-naphthol exhibits a decay of $1.8 \mathrm{~ns}$, while the anion displays a rise time of $0.6 \mathrm{~ns}$ and a decay with lifetime 8 ns. ${ }^{17}$

\section{Discussion}

Both the steady state and time resolved emission studies indicate that in the presence of SDS and PVP, the 1-naphthol molecules experience a microenvironment which is very different from that in SDS micelles or bulk water. It is evident
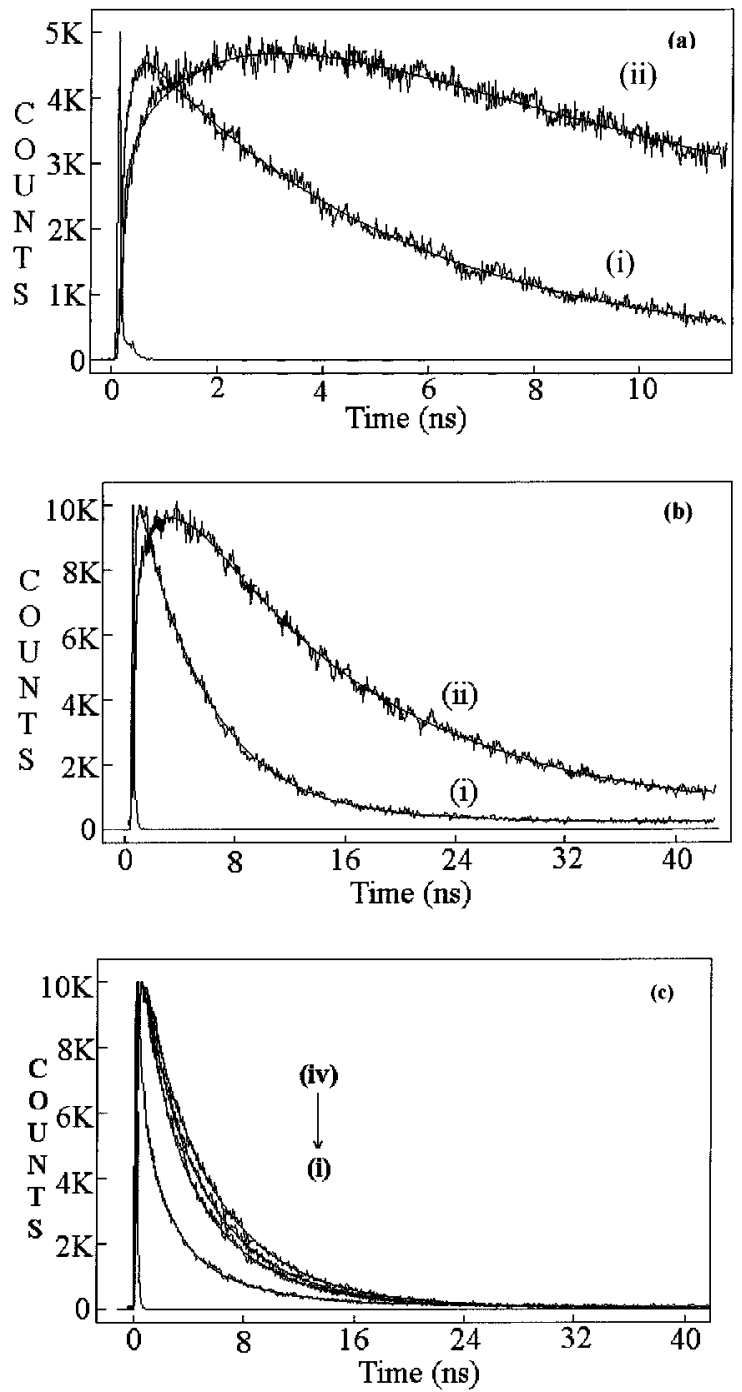

Figure 4. Fluorescence decays of $4 \times 10^{-5} \mathrm{M}$ aqueous 1-naphthol solution containing $4 \mathrm{mg}$ PVP per $\mathrm{mL}$ and (a) $[\mathrm{SDS}]=15 \mathrm{mM}$, resolution $=24 \mathrm{ps} / \mathrm{ch}$, (i) $\lambda_{\mathrm{em}}=360 \mathrm{~nm}$, (ii) $\lambda_{\mathrm{em}}=480 \mathrm{~nm}$; (b) [SDS] $=15 \mathrm{mM}$, resolution $=96 \mathrm{ps} / \mathrm{ch}$, (i) $\lambda_{\mathrm{em}}=360 \mathrm{~nm}$, (ii) $\lambda_{\mathrm{em}}=480 \mathrm{~nm}$; (c) resolution $=96 \mathrm{ps} / \mathrm{ch}, \lambda_{\mathrm{em}}=360 \mathrm{~nm}$, (i)-(iv) $[\mathrm{SDS}]=2.5,5,10$, and $15 \mathrm{mM}$.

that in the presence of PVP $(4 \mathrm{mg} / \mathrm{mL})$ and $15 \mathrm{mM}$ SDS, the neutral emission at $360 \mathrm{~nm}$ exhibits a biexponential decay with two components of $1.6 \mathrm{~ns}$ and $5.3 \mathrm{~ns}$. One of these components ( $1.6 \mathrm{~ns})$ is identical with the rise time of the anion emission at $460 \mathrm{~nm}$. This indicates the existence of two different microenvironments of the 1-naphthol molecules in the PVP-SDS complexes. In one of these environments, the 1-naphthol molecule undergoes deprotonation on a $1.6 \mathrm{~ns}$ time scale as indicated by the rise time of the anion emission. In the second environment, the 1-naphthol molecule does not undergo deprotonation at all. This results in a long lifetime of $5.3 \mathrm{~ns}$ and large intensity of the neutral emission. From the amplitudes of the $1.6 \mathrm{~ns}$ and $5.3 \mathrm{~ns}$ decay components of the $360 \mathrm{~nm}$ emission the population of the 1-naphthol molecules in the first and the second environment is inferred to be, respectively, $12 \pm 3 \%$ and $88 \pm 3 \%$.

From Scheme 1, it is evident that the PVP polymer chain shields major part of the SDS micellar aggregates from bulk water and keeps only a small part of the micelles exposed to bulk water. It seems that the 1-naphthol molecules which reside in the region of the SDS micelles completely shielded from bulk 
TABLE 1: Emission Parameters of 1-Naphthol in an Aqueous System Containing $4 \mathrm{mg}$ PVP Per mL and 15 MM SDS

\begin{tabular}{lccc}
\hline species & relative intensity $^{a}$ & rise time & \multicolumn{1}{c}{ decay time } \\
\hline neutral & 200 & & $1.6 \mathrm{~ns}(12 \%)^{b}, 5.3 \mathrm{~ns}(88 \%)^{\dagger}$ \\
anion & 0.75 & $1.6 \mathrm{~ns}$ & $13 \mathrm{~ns}$
\end{tabular}

${ }^{a}$ Relative to that in water. ${ }^{b} \pm 3 \%$.

TABLE 2: Lifetime of the Neutral Emission $(360 \mathrm{~nm})$ of 1-Naphthol in Aqueous Solution Containing 4 mg PVP per $\mathrm{mL}$ at Different Concentrations of SDS

\begin{tabular}{ccccc}
\hline$[\mathrm{SDS}](\mathrm{mM})$ & $a_{1}{ }^{a}$ & $\tau_{1}(\mathrm{~ns})$ & $a_{2}{ }^{a}$ & $\tau_{2}(\mathrm{~ns})$ \\
\hline 2.5 & 0.70 & 1.60 & 0.30 & 5.30 \\
5.0 & 0.40 & 1.60 & 0.60 & 5.30 \\
10.0 & 0.25 & 1.60 & 0.75 & 5.30 \\
15.0 & 0.12 & 1.60 & 0.88 & 5.30 \\
${ }^{a} \pm 0.03$. & & & &
\end{tabular}

TABLE 3: Emission Properties of 1-Naphthol in Water and $n$-Heptane

\begin{tabular}{lcccc}
\hline \multicolumn{1}{c}{ system } & $\lambda_{\mathrm{em}}(\mathrm{nm})$ & $\phi_{\mathrm{f}}$ & $\tau_{\mathrm{f}}(\mathrm{ns})$ & $k_{\mathrm{r}} \times 10^{-7}\left(\mathrm{sec}^{-1}\right)$ \\
\hline water & 460 & 0.11 & 8 & 1.4 \\
$n$-heptane & 360 & 0.12 & 6 & 2.0
\end{tabular}

water by the polymer chains, do not undergo ESPT at all and give rise to the intense emission at $360 \mathrm{~nm}$ with lifetime 5.3 ns. The 1-naphthol molecules which remain partially exposed to bulk water undergo ESPT on a $1.6 \mathrm{~ns}$ time scale, resulting in a decay component of $1.6 \mathrm{~ns}$ at $360 \mathrm{~nm}$ and a $1.6 \mathrm{~ns}$ rise time at $460 \mathrm{~nm}$.

The lifetime of decay of the anion (13 ns) emission band of 1-naphthol in the PVP-SDS complex is much longer than the lifetime of the 1-naphthol anion in water $(8 \mathrm{~ns}) .{ }^{14,17}$ This is in sharp contrast to the behavior in the presence of SDS alone. ${ }^{17}$ In the case of SDS micelles alone, lifetime of the 1-naphtholate anion is similar to that in water. ${ }^{17}$ This is presumably because of the fact that the anionic SDS micelles repel the naphtholate anion and expel it from the micelle to bulk water. However, in the case of the PVP-SDS aggregates it appears that the 1-naphthol anion remains bound to the polymer-surfactant aggregate and hence displays a lifetime very different from that in bulk water.

With increase in SDS concentration, the intensities of the neutral $(360 \mathrm{~nm})$ and the anion $(460 \mathrm{~nm})$ emission (Figure 1) and of the relative amplitudes of the $1.6 \mathrm{~ns}$ and $5.3 \mathrm{~ns}$ of the neutral emission (Figure 4c and Table 2) change markedly. This provides further support to the contention that broadly two different environments are present in the SDS-PVP aggregates. With increase in SDS concentration as more and more of SDSPVP complexes are formed, more 1-naphthol molecules are transferred to the region where the ESPT process is blocked. This results in an increase in the intensity and the relative contribution of the $5.3 \mathrm{~ns}$ component of the neutral emission but reduces relative amount of the anion formed. As a result, intensity of the anion emission decreases at high SDS concentration $(>5 \mathrm{mM})$.

A semiquantitative explanation of the observed relative emission quantum yields of the neutral $\left(\phi^{\mathrm{N}_{\mathrm{f}}}\right)$ form and the anion $\left(\phi^{\mathrm{A}}\right.$ ) form of 1-naphthol in the presence of $15 \mathrm{mM}$ SDS and PVP ( $4 \mathrm{mg} / \mathrm{mL}$ ) may be as follows. Since $12 \pm 3 \%$ of the molecules undergo ESPT to form the anion and $88 \pm 3 \%$ do not undergo ESPT at all, and since $\phi_{\mathrm{f}}$ is a product of radiative rate constant $\left(k_{\mathrm{r}}\right)$ and lifetime (1.6 and $5.3 \mathrm{~ns}$ for the neutral form and $13 \mathrm{~ns}$ for the anion),

$$
\phi_{\mathrm{f}}^{\mathrm{N}}=0.12 \times 1.6 \times k_{\mathrm{r}}^{\mathrm{N}}+0.88 \times 5.3 \times k_{\mathrm{r}}^{\mathrm{N}}
$$

and

$$
\phi_{\mathrm{f}}^{\mathrm{A}}=0.12 \times 13 \times k_{\mathrm{r}}^{\mathrm{A}}
$$

The radiative rate constants $\left(k_{\mathrm{r}}=\phi_{\mathrm{f}} / \tau_{\mathrm{f}}\right)$ for the neutral and the anion form of 1-naphthol were obtained as follows. The $\phi_{\mathrm{f}}$ and $\tau_{\mathrm{f}}$ of 1-naphthol were determined in water and in $n$-heptane. In water, anion emission is observed exclusively, and hence $k_{\mathrm{r}}(1.4$ $\times 10^{7} \mathrm{sec}^{-1}$ ) in water corresponds to the anion. On the other hand, in $n$-heptane the emission originates from the neutral form, and hence $k_{\mathrm{r}}\left(2 \times 10^{7} \mathrm{sec}^{-1}\right)$ in $n$-heptane corresponds to the neutral form. Using these, from eq 1 the ratio of quantum yields, $\phi_{\mathrm{f}} \mathrm{N} / \phi_{\mathrm{f}} \mathrm{A}$ is calculated to be $4.3 \pm 1$. To get this ratio experimentally, we decomposed the observed emission spectrum in 4 $\mathrm{mg}$ PVP per $\mathrm{mL}$ and $15 \mathrm{mM}$ SDS into two spectra arising from the neutral and the anion form (Figure 5). The ratio of the area of these two emission spectra is $4 \pm 0.5$. Obviously, the experimentally observed ratio $(4 \pm 0.5)$ is very similar to the calculated one $(4.3 \pm 1)$.

It is reasonable to expect that in the two environments of PVP-SDS aggregates, 1-naphthol would exhibit different absorption and excitation spectra. To check the solvent dependence of the excitation spectrum of the neutral and the anion form, we compared the excitation spectrum at $460 \mathrm{~nm}$ (anion emission) in water with that at $360 \mathrm{~nm}$ (neutral emission) in $n$-heptane. As shown in Figure 6, the excitation spectra in water and $n$-heptane show identical features with a strong peak at $\sim 290 \mathrm{~nm}$, a shoulder at $\sim 310 \mathrm{~nm}$, and a weak peak at $\sim 320$ $\mathrm{nm}$, which are the same as the absorption spectrum given in Figure 3. This shows that absorption and excitation spectra (of both neutral and anion emission) of 1-naphthol do not depend on environment. Hence, in the presence PVP $(4 \mathrm{mg} / \mathrm{mL})$ and SDS $(15 \mathrm{mM})$, the excitation spectra of the neutral $(360 \mathrm{~nm})$ and the anion form $(460 \mathrm{~nm})$ are identical and same as the absorption spectrum (Figure 3).

The discrepancy between the value of the CAC reported in this work $(0.8 \mathrm{mM})$ and that reported by Narenberg et al. $(0.3$ $\mathrm{mM})^{1}$ may be explained as follows. Narenberg et al. ${ }^{1}$ used SDS molecules covalently attached to a fluorescent probe. They studied the interaction of a mixture of labeled and unlabeled SDS surfactants with PVP. Evidently, in their experiment the fluorescent probe was always in contact with the surfactants and the polymers, and contributions from the free probe in bulk water are completely eliminated. In our experiment, the probe 1-naphthol is not covalently linked to either the polymer (PVP) or the surfactant (SDS). Thus in our case, until a finite amount of SDS-PVP aggregates are formed, the probe does not bind to it hydrophobically and stays freely in bulk water. As a result, the CAC reported by us is higher than that reported by Narenbery et al. ${ }^{1}$ It will be interesting to study interactions between PVP and SDS, using SDS molecules covalently attached to 1-naphthol.

\section{Conclusion}

The present work indicates that 1-naphthol readily binds to the PVP-SDS aggregates, and the ESPT process of 1-naphthol is a sensitive indicator of the interaction of the polymer, PVP, and the surfactant SDS. The intensity of the neutral emission shows a break at $0.8 \mathrm{mM}$ of SDS, which is the CAC for the PVP-SDS system. The CAC determined in this work is close to that $(0.3 \mathrm{mM})$ observed in fluorescence correlation spectroscopy $^{1}$ and is nearly 10 times lower than the CMC of SDS. The 


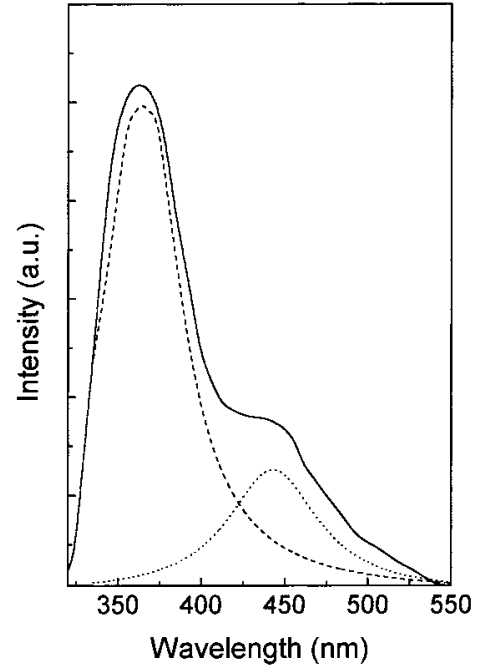

Figure 5. Decomposition of the emission spectrum of 1-naphthol in PVP ( $4 \mathrm{mg} / \mathrm{mL}$ ) and $15 \mathrm{mM}$ SDS into neutral and anion emission; experimental curve (-), neutral emission (- - ), and anion emission $(\cdots)$

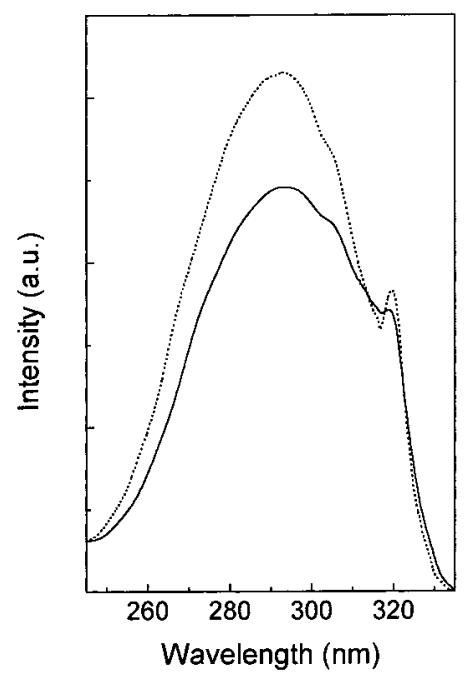

Figure 6. Excitation spectra of 1-naphthol (i) in water at $460 \mathrm{~nm}(-)$ and (ii) in $n$-heptane at $360 \mathrm{~nm}(\cdots)$.

steady state spectra and the decay parameters of the neutral (360 $\mathrm{nm})$ and anion (460 nm) emission of 1-naphthol bound to PVP (4 mg PVP per $\mathrm{mL})-$ SDS $(15 \mathrm{mM}$ ) are very different from those of 1-naphthol in $200 \mathrm{mM} \mathrm{SDS}$ reported in earlier work. ${ }^{17}$ The maximum enhancement of the intensity of the neutral emission caused by $4 \mathrm{mg}$ PVP per $\mathrm{mL}$ and $15 \mathrm{mM}$ SDS is 200 times, which is nearly double the maximum enhancement of 90 times observed in $>140 \mathrm{mM}$ SDS. ${ }^{17}$ In the PVP-SDS complex, only $12 \pm 3 \%$ of the 1-naphthol molecules undergo deprotonation on a $1.6 \mathrm{~ns}$ time scale, while a vast majority ( 88 $\pm 3 \%$ ) do not undergo deprotonation at all, and for them, the neutral emission exhibits a 5.3 ns lifetime. Unlike in SDS micelles, the anion of 1-naphthol remains bound to the PVPSDS complex and displays a lifetime (13 ns) very different from that in bulk water $\left(8 \mathrm{~ns}^{14,17}\right)$. In summary, the microenvironment of the probe 1-naphthol in PVP-SDS complex is very different from that in SDS micelles. In PVP-SDS complexes there are broadly two different microenvironments. In one of them, the polymer chain shields the probe 1-naphthol molecules from bulk water, resulting in almost total suppression of the deprotonation process. In the other environment, the probe remains partially exposed to the water molecules, and as a result the ESPT process occurs though in a time scale much slower than that in bulk water. This is consistent with the "necklace model"3,5 depicted in Scheme 1.

Acknowledgment. Thanks are due to Council of Scientific and Industrial Research (CSIR), Government of India for generous research grants. D.S., S.K.P., D.M., and S.S. thank CSIR for awarding fellowships.

\section{References and Notes}

(1) Narenberg, R.; Kliger, J.; Horn, D. Angew Chem., Int Ed. Engl. 1999, $38,1626$.

(2) Macknight, W. J.; Ponomarenko, E. A.; Tirrell, D. A. Acc. Chem. Res. 1998, 31, 789.

(3) Gilanyi, T. J. Phys. Chem. B 1999, 103, 2085. 379.

(4) Zanette, P.; Frescura, V. L. A. J. Colloid Interface Sci. 1999, 213,

(5) Nikas, Y. J.; Blankschtein, D. Langmuir 1994, 10, 3512.

(6) Xia, T.; Dubin, P. L.; Kim Y. J. Phys. Chem. 1992, 96, 6805. 14.

(7) Maltesh, C.; Somasundaran, N. J. Colloid Interface Sci. 1993, 157,

(8) Nagarajan, R. J. Chem. Phys. 1989, 90, 1980.

(9) Gao, Z.; Wasylishen, R. E.; Kwak, J. C. T. J. Phys. Chem. 1991, $95,462$.

(10) Goddard, E. D. In Interaction of Surfactants with Polymers and Proteins; Goddard, E. D, Ananthapadmanabhan, E. P., Eds.; CRC: Boca Raton, Fl, 1993.

(11) Zana, R.; Lang, J.; Lianos, P. In Microdomains in Polymer Solutions; Dubin, P. L., Ed.; Plenum: New York, 1985; p 357.

(12) Cabane, B.; Duplessix, R. J. Phys. (Paris) 1982, 43, 1529.

(13) (a) Kolomeisky, A. B.; Widom, B. Faraday Discuss. 1999, 112, 81. (b) Lum, K.; Chandler, D.; Weeks, J. D. J. Phys. Chem. B 1999, 103, 4570.

(14) (a) Webb, S. P.; Yeh, S. W.; Philips, L. A.; Tolbert, M. A.; Clark, J. H. J. Am. Chem. Soc. 1984, 106, 7286. (b) Robinson, G. W.; Thistlewaite, P. S.; Lee, J. J. Phys. Chem. 1986, 90, 4224 (c) Lee, J.; Robinson, G. W.; Webb, S. P.; Philips, L. A.; Clark, J. H. J. Am. Chem. Soc. 1986, 108, 6538 .

(15) (a) Douhal, A.; Lahmani, F.; Zewail, A. H. Chem. Phys. 1996, 207, 477. (b) Kim, S. K.; Li, S.; Bernstein, E. R. J. Chem. Phys. 1991, 81, 3119. (c) Kim, S. K.; Breen, J. J.; Wilberg, D. M.; Peng, L. W.; Heikal, A.; Syage, J. A.; Zewail, A. H. J. Phys. Chem. 1995, 99, 7421. 6904.

(16) Hansen, J. E.; Pines, E.; Fleming, G. R. J. Phys. Chem. 1992, 96,

(17) Mandal, D.; Pal, S. K.; Bhattacharyya, K. J. Phys. Chem. A 1998, 102,9710 .

(18) Sujatha, J.; Mishra, A. K. Langmuir 1998, 14, 2256.

(19) (a) Ramamurthy, V.; Laksminarasimhan, P. H.; Grey, C. P.; Johnsten, L. J. J. C. S. Chem. Commun. 1998, 2411. (b) Politi, M. J.; Brandt, O.; Fendler, J. H. J. Phys. Chem. 1985, 89, 2345. (c) Pal, S. K.; Mandal, D.; Bhattacharyya, K. J. Phys. Chem. B 1998, 102, 11017. 